\title{
OpenIFS@ home version 1: a citizen science project for ensemble weather and climate forecasting
}

\author{
Sarah Sparrow ${ }^{1}$, Andrew Bowery ${ }^{1}$, Glenn D. Carver ${ }^{2}$, Marcus O. Köhler ${ }^{2}$, Pirkka Ollinaho $^{4}$, Florian Pappenberger ${ }^{2}$, \\ David Wallom $^{1}$, and Antje Weisheimer ${ }^{2,3}$ \\ ${ }^{1}$ Oxford e-Research Centre, Engineering Science, University of Oxford, Oxford, UK \\ ${ }^{2}$ European Centre for Medium-Range Weather Forecasts (ECMWF), Reading, UK \\ ${ }^{3}$ National Centre for Atmospheric Science (NCAS), Physics department, University of Oxford, Oxford, UK \\ ${ }^{4}$ Finnish Meteorological Institute (FMI), Helsinki, Finland
}

Correspondence: Sarah Sparrow (sarah.sparrow@oerc.ox.ac.uk)

Received: 30 June 2020 - Discussion started: 30 September 2020

Revised: 27 January 2021 - Accepted: 5 February 2021 - Published: 9 June 2021

\begin{abstract}
Weather forecasts rely heavily on general circulation models of the atmosphere and other components of the Earth system. National meteorological and hydrological services and intergovernmental organizations, such as the European Centre for Medium-Range Weather Forecasts (ECMWF), provide routine operational forecasts on a range of spatio-temporal scales by running these models at high resolution on state-of-the-art high-performance computing systems. Such operational forecasts are very demanding in terms of computing resources. To facilitate the use of a weather forecast model for research and training purposes outside the operational environment, ECMWF provides a portable version of its numerical weather forecast model, OpenIFS, for use by universities and other research institutes on their own computing systems.

In this paper, we describe a new project (OpenIFS@ home) that combines OpenIFS with a citizen science approach to involve the general public in helping conduct scientific experiments. Volunteers from across the world can run OpenIFS@home on their computers at home, and the results of these simulations can be combined into large forecast ensembles. The infrastructure of such distributed computing experiments is based on our experience and expertise with the climateprediction.net (https:// www.climateprediction.net/, last access: 1 June 2021) and weather@home systems.

In order to validate this first use of OpenIFS in a volunteer computing framework, we present results from ensembles of forecast simulations of Tropical Cyclone Karl from
\end{abstract}

September 2016 studied during the NAWDEX field campaign. This cyclone underwent extratropical transition and intensified in mid-latitudes to give rise to an intense jet streak near Scotland and heavy rainfall over Norway. For the validation we use a 2000-member ensemble of OpenIFS run on the OpenIFS@ home volunteer framework and a smaller ensemble of the size of operational forecasts using ECMWF's forecast model in 2016 run on the ECMWF supercomputer with the same horizontal resolution as OpenIFS@ home. We present ensemble statistics that illustrate the reliability and accuracy of the OpenIFS@home forecasts and discuss the use of large ensembles in the context of forecasting extreme events.

\section{Introduction}

Today there are many ways in which the public can directly participate in scientific research, otherwise known as citizen science. The types of projects on offer range from data collection or generation, for example taking direct observations at a particular location, such as in the British Trust for Ornithology's "Garden BirdWatch" (Royal Society for the Protection of Birds (RSPB), 2021); through data analysis, such as image classification in projects such as Zooniverse's galaxy classification (Simpson et al., 2014); and finally data processing. This final class of citizen science includes those projects where citizens donate time on their computer to execute project applications. Examples of this class of citizen 
science project are known as volunteer or crowd computing applications. There is an extremely wide variety of different projects making use of this paradigm, the most wellknown of which is searching for extra-terrestrial life with SETI@home (Sullivan III et al., 1997). Projects of this type are underpinned by the Berkeley Open Infrastructure for Network Computing (BOINC, Anderson, 2004) that distributes simulations to the personal computers of their public volunteers that have donated their spare computing resources.

For over 15 years, one such BOINC-based project, ClimatePrediction.net (CPDN) has been harnessing public computing power to allow the execution of large ensembles of climate simulations to answer questions on uncertainty that would otherwise not be possible to study using traditional high-performance computing (HPC) techniques (Allen, 1999; Stainforth et al., 2005). Volunteers can sign up to CPDN through the project website and are engaged and retained through the mechanisms detailed in Christensen et al. (2005). As well as facilitating large-ensemble climate simulations, the project has also increased public awareness of climate-change-related issues. Through the CPDN platform, volunteers are notified of the scientific output that they have contributed towards (complete with links to the academic publication) and through the project forums and message boards can engage directly with scientists about the experiments being undertaken. Public awareness is also raised by press coverage of the project (e.g. "Gadgets that give back: awesome eco-innovations, from Turing Trust computers to the first sustainable phone" by Margolis, 2021, or "Climate Now I Five ways you can become a citizen scientist and help save the planet" by Daventry, 2020), scientific outputs (e.g. "'weather@home' offers precise new insights into climate change in the West" by Oregon State University, 2016; "How your computer could reveal what's driving record rain and heat in Australia and NZ" by Smyrk and Minchin, 2014; "Looking, quickly, for the fingerprints of climate change" by Fountain, 2016), and through live experiments undertaken directly with media outlets such as The Guardian (Schaller et al., 2016) and British Broadcasting Corporation (BBC, Rowlands et al., 2012). To date, the analysis performed by CPDN scientists and volunteers can be broadly classified into three different themes. The first is climate sensitivity analysis, where plausible ranges of climate sensitivity are mapped through generating large, perturbed parameter ensembles (e.g. Millar et al., 2015; Rowlands et al., 2012; Sparrow et al., 2018b; Stainforth et al., 2005; Yamazaki et al., 2013). The second is simulation bias reduction methods through perturbed parameter studies (e.g. Hawkins et al., 2019; Li et al., 2019; Mulholland et al., 2017). The third category is extreme weather event attribution studies where quantitative assessments are made of the change in likelihood of extreme weather events occurring between past, present, and possible future climates (e.g. Li et al., 2020; Otto et al., 2012; Philip et al., 2019; Rupp et al., 2015; Schaller et al., 2016; Sparrow et al., 2018a).
To increase confidence in the outcomes of large-ensemble studies it is desirable to compare results across multiple different models. Whilst large (on the order of 100 members) ensembles can be (and are) produced by individual modelling centres, this requires a great deal of coordination across the community on experimental design and output variables. The computing resources required to produce very large (> 10000-member) ensembles are not readily available outside of citizen science projects such as CPDN. Therefore, enabling new models to work within this infrastructure to address questions such as those outlined above is very desirable.

In this paper we detail the deployment of the European Centre for Medium-Range Weather Forecasts (ECMWF) OpenIFS model within the CPDN infrastructure as the OpenIFS@home application. This new facility enables the execution of ensembles of weather forecast simulations (ranging from 1 to $10000+$ members) at scientifically relevant resolutions to achieve the following goals.

- To study the predictability of forecasts, especially for high-impact extreme events.

- To explore interesting past weather and climate events by testing sensitivities to physical parameter choices in the model.

- To help the study of probabilistic forecasts in a chaotic atmospheric flow and reduce uncertainties due to nonlinear interactions.

- To support the deployment of current experiments performed with OpenIFS to run in OpenIFS@ @ome provided certain resource constraints are met.

\section{The ECMWF OpenIFS model}

The OpenIFS activity at ECMWF began in 2011, with the objective of enabling the scientific community to use the ECMWF Integrated Forecast System (IFS) operational numerical weather prediction model in their own institutes for research and education. OpenIFS@ @ome as described in this paper uses the OpenIFS release based on IFS cycle 40 release 1, the ECMWF operational model from November 2013 to May 2015. The OpenIFS model differs from IFS as the data assimilation and observation processing parts are removed from the OpenIFS model code. The forecast capability of the two models is identical, however, and the OpenIFS model supports ensemble forecasts and all resolutions up to the operational resolution. OpenIFS consists of a spectral dynamical core, a comprehensive set of physical parameterizations, a surface model (HTESSEL), and an ocean wave model (WAM). A more detailed description of OpenIFS can be found in Appendix A. The relative contribution of model improvements, reduction in initial state error and increased 
use of observations to the IFS forecast performance is discussed in detail in Magnusson and Källén (2013). A detailed scientific and technical description of IFS can be found in open-access scientific manuals available from the ECMWF website (ECMWF, 2014a-d).

\section{OpenIFS@home BOINC application}

\subsection{Technical requirements and challenges}

When creating a new volunteer computing project, there are a number of requirements for both the science team developing it and the citizen volunteers that will execute it. As such they can be considered boundary constraints. These are listed below.

1. The model used to build the BOINC application should be unchanged. There are two main advantages to this. First, the model itself does not require extensive revalidation. Second, if errors are found within the BOINCbased model, an identically configured non-BOINC version may be executed locally for diagnostic purposes. As OpenIFS is currently designed for simulation on Unix or Linux systems, initial development of OpenIFS@ home has also been limited to this platform, thereby preventing the need for a detailed revalidation. Consequently, OpenIFS@home is currently limited to the Linux CPDN volunteer population, around $10 \%$ of the 10000 active volunteers registered with CPDN.

2. The model configuration for an experiment and the formulation of initial conditions and ancillary files should remain unchanged from that used in a standard OpenIFS execution to allow easy support by the OpenIFS team in ECMWF and debugging by the CPDN.

3. Configuration of the ensembles should be simple, requiring minimal changes to input files to launch a large batch of simulations. Web forms developed for this minimize the possibility of error in the configuration.

4. Model performance, when running on volunteers' systems, should be acceptable such that results are produced at a useful frequency for the submitting researcher and so that the time to completion of an individual simulation workunit is practical for the volunteers' systems. This dictates the resolution of the simulation that can be run; a lower resolution than that utilized operationally, but one that is still scientifically useful.

5. The model must not generate excessive volumes of output data such that volunteers' network connections are overwhelmed. This requires integration of existing measures to analyse the model configuration so that the CPDN team can validate the expected data volumes before submission.
6. The model binary executable needs to minimize dependencies on the specific configuration of the system found on the volunteer computers. Therefore, the compilation environment for OpenIFS@ home needs to use statically linked libraries wherever possible, distributing these in a single application package.

\subsection{Porting OpenIFS to a BOINC environment}

To optimize OpenIFS for execution within BOINC on volunteer systems there are a number of changes that are required to the model beyond setup and configuration changes. The majority of these may be classified in terms of understanding and restricting the application footprint in terms of both overall size and resource usage during execution.

OpenIFS is designed to work efficiently across a range of computing systems, from massively parallel highperformance computing systems to a single multi-core desktop. As BOINC operates optimally if each application execution is restricted to a single core on a client system, understanding and reducing memory usage becomes a priority, determining possible resolutions the model can be executed at. During the initial application development, a spectral resolution of T159, equivalent to a grid spacing of approximately $125 \mathrm{~km}$ (see the Appendix for more details of the model's grid structure) with 60 vertical level was chosen to ensure execution would complete within 1 or $2 \mathrm{~d}$ whilst still maintaining satisfactory scientific performance. Typical CPDN simulations run for considerably longer, allowing flexibility in future utilization of this application.

Since OpenIFS@ home will run on a single computer core, the MPI (message passing) parallel library was removed from the OpenIFS code, though the ability to use OpenMP was retained for possible future use. This reduces the memory footprint and size of the binary executable.

A model restart capability is necessary as the volunteer computer may be shutdown at any point in the execution. OpenIFS provides a configurable way of enabling exact restarts, with an option to delete older restart files. This was added to the model configuration to prevent excessive disk use on the volunteer's computers.

There is also the requirement to transfer to volunteer systems the configuration files that control the execution of the model and the return of model output files. The design of OpenIFS makes it inherently suitable for deployment under BOINC. Input and output files use the standard GRIB format (World Meteorological Organization (WMO), 2003) that was originally designed for transmission over slow telecommunication lines. The model output files are separated into spectral and grid point fields. Each model level of each field is encoded in a self-describing format, whilst the field data itself is packed into a specified "lossy" bit precision. This greatly reduces the amount of data transmission, whilst the self-describing nature of each of the GRIB fields supports a "trickle" of output results as the model runs. Scientists are 


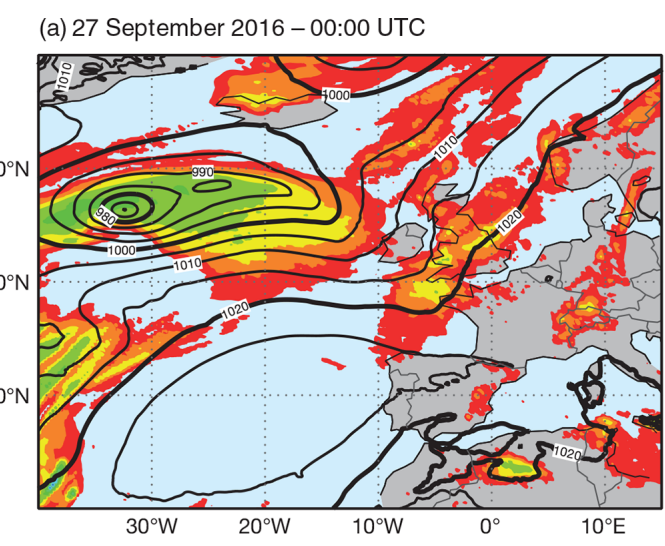

(c) 28 September 2016 - 00:00 UTC

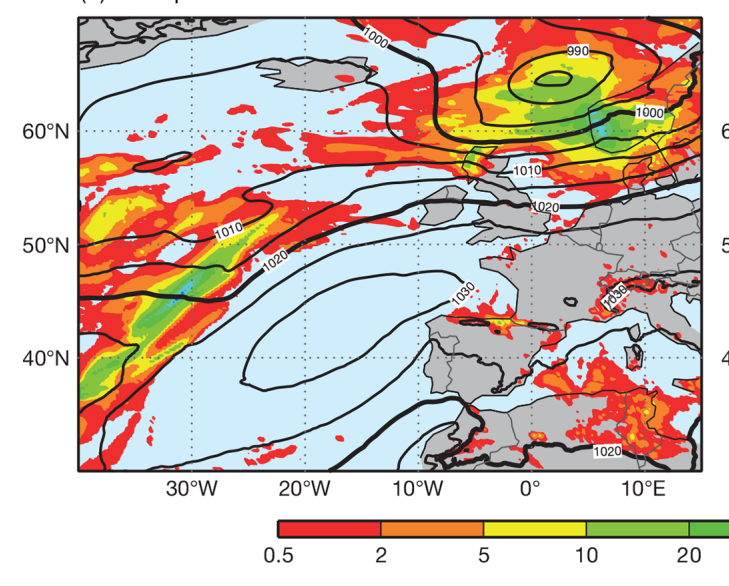

(b) 27 September $2016-12: 00$ UTC

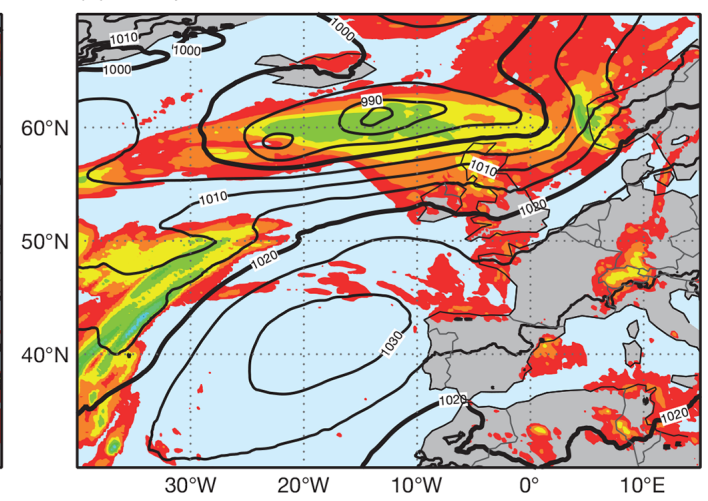

(d) 28 September $2016-12: 00$ UTC

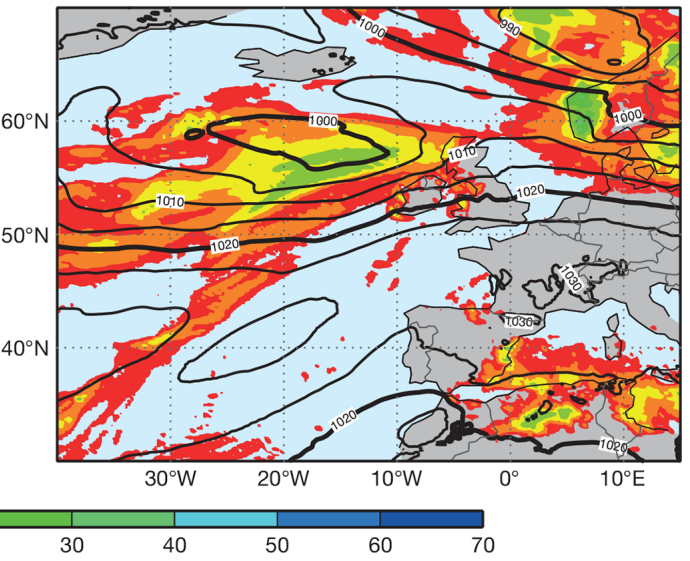

Figure 1. Evolution of Tropical Cyclone Karl on 27 and 28 September 2016 showing the downstream impact with heavy rainfall over western Norway. Contour lines display mean sea level pressure (hPa) from the ECMWF operational analysis. Colour shading shows the 12-hourly accumulated total precipitation $(\mathrm{mm})$ from the ECMWF operational forecast.

expected to carefully choose the model fields and levels required to minimize output file sizes and transmission times to the CPDN servers. This is an optimization exercise that is supported by CPDN, with exact thresholds depending on frequency of return as well as absolute file size due to differences in volunteer's internet connectivity.

The GRIB-1 and GRIB-2 definitions do, however, introduce one difficulty. The encoding of the ensemble member number only supports values up to 255 . To overcome this, custom changes were made to the output GRIB files to allow exploitation of the much larger ensembles that could be distributed within OpenIFS@ home. Specifically, four spare bytes in the output grid point GRIB fields were used to create a custom ensemble perturbation number (defined in local part of section 1 in GRIB-1 output; section 3 of GRIB-2 output). The custom GRIB templates must be distributed with the model to the volunteer's computer and subsequently used when decoding the returned GRIB output files.

\section{Demonstration}

\subsection{Case study: Tropical Cyclone Karl}

Recent research into mid-latitude weather predictability has focused on the role of diabatic processes. Research flight campaigns provide in situ measurements of diabatic and other physical processes against which models can be validated. The NAWDEX flight campaign (Schäfler et al., 2018) focused on weather features associated with forecast errors, for example the poleward recurving of tropical cyclones, which is known to be associated with low predictability (Harr et al., 2008). To demonstrate the new OpenIFS@ @ome facility, we simulated the later development of a tropical cyclone (TC) in the North Atlantic that occurred during the NAWDEX campaign. In September 2016, TC Karl underwent extratropical transition and its path moved far into the mid-latitudes. The storm resulted in high-impact weather in north-western Europe (Euler et al., 2019). After leaving the subtropics on 25 September, ex-TC Karl moved northwards and merged with a weak pre-existing cyclone. This resulted in rapid intensification and the formation of an unusually 
strong jet streak downstream near Scotland $2 \mathrm{~d}$ later. This initiated further development with heavy and persistent rainfall over western Norway.

\subsection{Experimental setup and initial conditions}

A $6 \mathrm{~d}$ forecast experiment was designed to capture the extratropical transition of TC Karl and the associated high impact weather north of Scotland and near the Norwegian west coast. The forecasts were initialized on 25 September 2016 at 00:00 UTC (see Fig. 1). The wave model was switched off in OpenIFS for this experiment. Compared to the operational forecasting system at ECMWF and other major weather centres, the OpenIFS grid resolution used here is coarse ( $\sim 125 \mathrm{~km}$ grid spacing) and hence the model's ability to resolve orographic effects over smaller scales will be limited.

To represent the uncertainty in the initial conditions and to evaluate the range of possible forecasts, a 2000-member ensemble with perturbed initial conditions was launched. The ECMWF data assimilation system was used to create 250 perturbed initial states. Each of these 250 states was then used for eight forecasts in the 2000-member ensemble. A different forecast realisation for each set of eight forecasts was generated by enabling the stochastic noise in the OpenIFS physical parameterizations.

The initial-state perturbations in the ECMWF operational IFS ensemble are generated by combining so-called singular vectors (SVs) with an ensemble of data assimilations (EDA) (Buizza et al., 2008; Isaksen et al., 2010; Lang et al., 2015). The SVs represent atmospheric modes that grow rapidly when perturbed from the default state. In the operational IFS ensemble, the modes that result in maximum total energy deviations in a $48 \mathrm{~h}$ forecast lead time are targeted. A total of 50 of these modes are searched for in the Northern Hemisphere, 50 are searched for in the Southern Hemisphere, and 5 modes per active tropical cyclone are searched for in the tropics. The final SV initial-state perturbation fields are constructed as a linear combination of the found SVs (Leutbecher and Palmer, 2008). The EDA-based perturbations, on the other hand, try to assess uncertainties in the observations (and the model itself) used in the data assimilation (DA). This is achieved by running the IFS DA at a lower resolution multiple times and applying perturbations to the used observations and the model physics. In the operational IFS ensemble, 50 of these DA cycles are run (Lang et al., 2019). The final perturbation fields that the operational IFS ensemble uses are a combination of both of the perturbed fields. Here, we apply the same methodology as in the operational IFS ensemble initialization. The only differences are that (i) the used model version and resolution differ from the operational setup, (ii) only $25 \mathrm{DA}$ cycles are run with a \pm symmetry to construct 50 initial states, and (iii) we calculate $250 \mathrm{SV}$ modes in the extra-tropics, instead of the default 50. This was motivated by the discussion in (Leutbecher and
Lang, 2014). The Stochastically Perturbed Parameterization Tendencies (SPPT) scheme (Buizza et al., 2007; Palmer et al., 2009; Shutts et al., 2011) was used on top of the initial state perturbations to represent model error in the ensemble.

The results from this experiment were compared against output from an ensemble of the same size as ECMWF's operational forecasts (51 members) run at the same horizontal resolution as our forecast experiment using the current operational IFS cycle at the time of writing (CY46R1).

\subsection{Performance}

\subsubsection{BOINC application performance}

Figure 2a shows the behaviour of the batch of simulations (OpenIFS@ @ome dashboard, ClimatePrediction.net, 2019), detailing how long simulations were in the queue (yellow), took to run (purple), and took to accumulate an ensemble of successful results (blue). The overall percentage of successfully completed runs in the batch compared to those distributed is also shown in the title. Medians rather than means are quoted as distributions can have long tails. This is due to the nature of the computing resources used, where for a variety of reasons a small number of simulations (work units) may go to systems that may not run or connect to the internet for a non-trivial period after receiving work. This validation batch was run on the CPDN development site where fewer systems are connected than on the main site, but they are more likely to be running continuously. The median queue time was $45.64 \mathrm{~h}$, and the $6 \mathrm{~d}$ simulations had a median runtime of $3.25 \mathrm{~h}$ across the different volunteer machines. Half of the batch (i.e. $50 \%$ of the ensemble) was returned after $51.76 \mathrm{~h}$ with $80 \%$ completion (the criteria typically chosen for closure of a batch) being achieved after $80.68 \mathrm{~h}$. The median run time distribution (purple) shows a bi-modal structure that reflects the different system specifications and project connectivity of client machines connected to the development site. As detailed in Anderson (2004) and Christensen et al. (2005), each volunteer can configure their own project connectivity and available resources as well as specify during which times their system can be used to compute work, and thus these timings should be viewed as indicative rather than definitive. Figure $2 b$ shows how the run time from a representative batch of OpenIFS@home simulations compares to the other UK Met Office model configurations available on the CPDN platform (although typically these are used to address different questions) and demonstrates that not only is the OpenIFS@ home run time comparable to the different embedded regional models in weather@home, it is also among the faster running models on the platform. The OpenIFS@ home application running at this resolution (T159L60) requires $3.2 \mathrm{~Gb}$ of storage and $5.37 \mathrm{~Gb}$ of random access memory (RAM).

Although individual simulations will not necessarily be bit reproducible when run on systems with different operating 


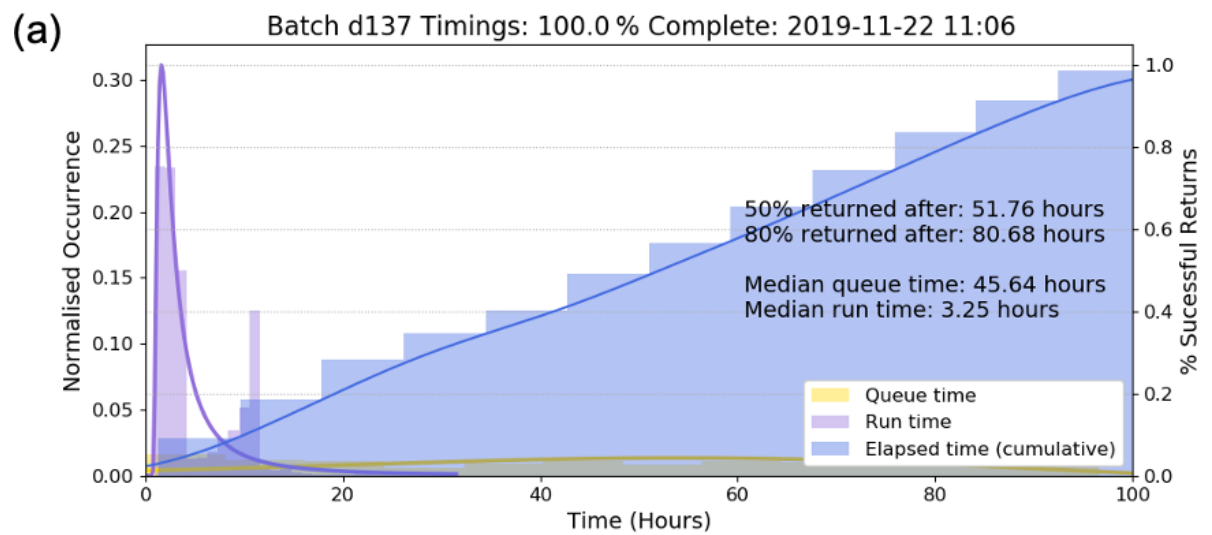

(b)

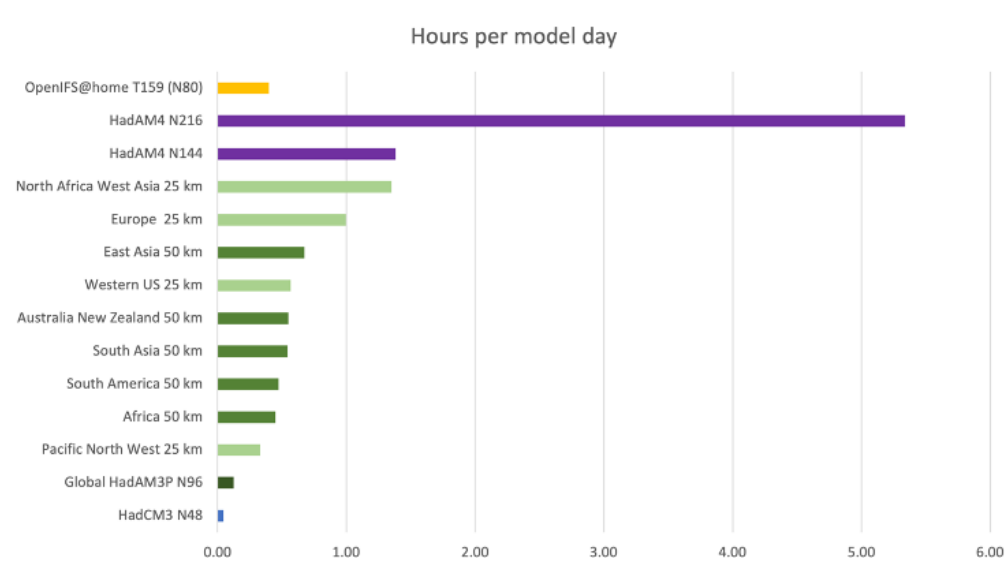

Figure 2. (a) The relevant timings associated with the validation batch. The queue time (yellow) and run time (purple) distributions are straight occurrence distributions, whereas the elapsed time (blue) is a cumulative distribution expressed as a percentage of the successful returns. (b) Run time information in hours per model day based on a representative batch for applications on the CPDN platform (note these numbers are indicative rather than definitive). ECMWF OpenIFS@ home is depicted in yellow, UK Met Office weather@home (HadAM3P with various HadRM3P regions) configurations are depicted in green (with light green indicating a $25 \mathrm{~km}$ embedded region, green indicating a $50 \mathrm{~km}$ embedded region, and dark green indicating where only the global driving model is computed). The UK Met Office low-resolution coupled atmosphere-ocean model HadCM3 is shown in blue, and the high-resolution global atmosphere HadAM4 at N144 ( 90 km midlatitudes) and N216 ( $60 \mathrm{~km}$ mid-latitudes $)$ are shown in purple.

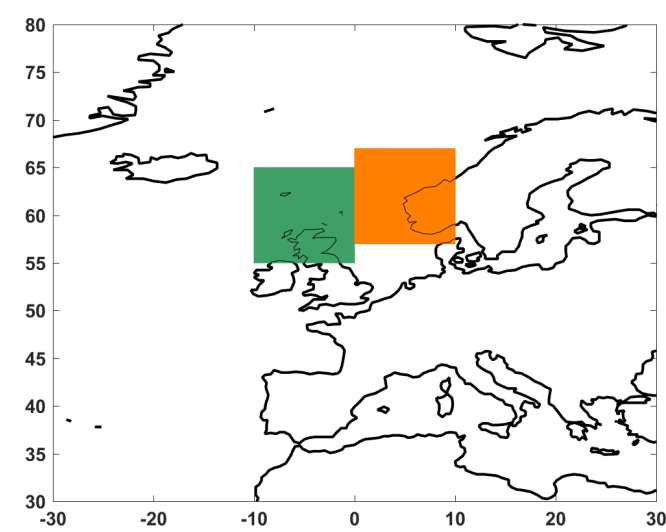

Figure 3. Two regions over northern Scotland (green) and around Bergen (orange) that have been used in the diagnostics of the model performance. systems and processor types. Knight et al. (2007) demonstrate the effect of hardware and software is small relative to the effect of parameter variation and can be considered equivalent to those differences caused by changes in initial conditions. Given the large ensembles involved, the properties of the distributions themselves are not expected to be affected by different mixes of hardware in computing individual ensemble members.

\subsubsection{Meteorological performance}

TC Karl, as it moved eastward across the North Atlantic, was associated with a band of low surface pressure that reached over a region of northern Scotland $60 \mathrm{~h}$ into the forecasts and near Bergen on the coast of Norway at $72 \mathrm{~h}$ (see green and orange boxes in Fig. 3 for the regions). 
(a)

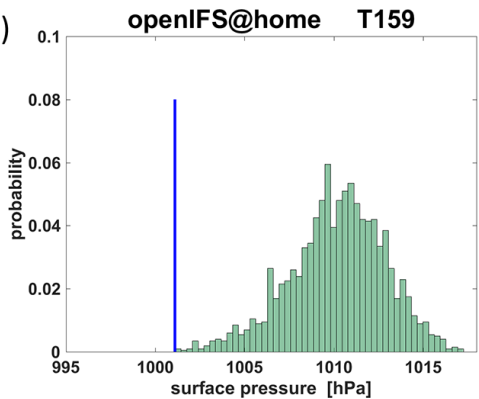

(d)

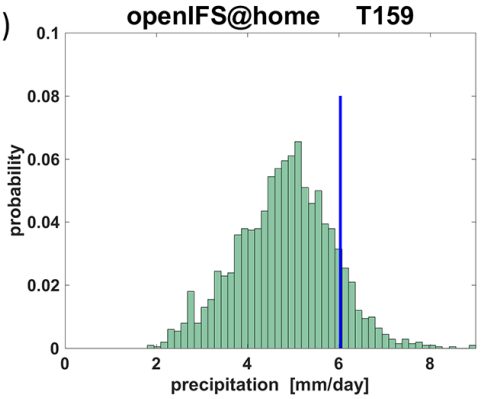

(b) 0.3

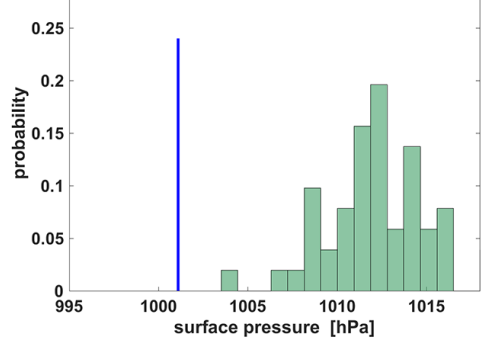

(e)

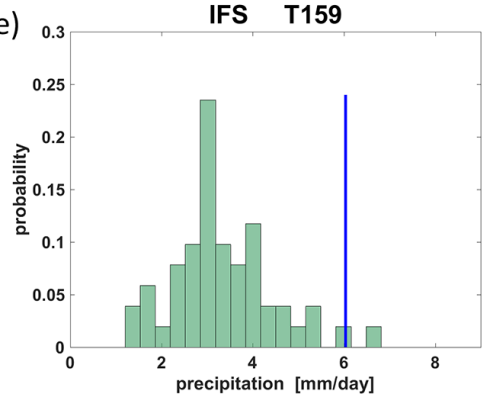

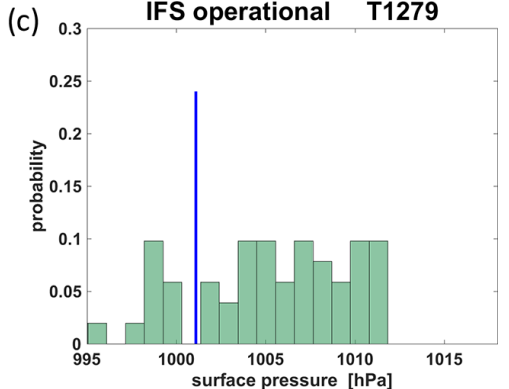

(c)

(f)

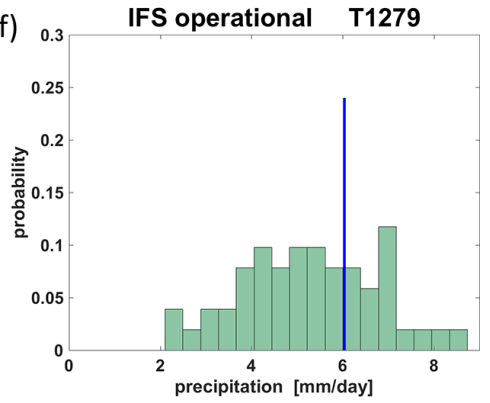

Figure 4. Ensemble forecast distribution in northern Scotland of mean sea level pressure (a-c) and total precipitation (d-f) in the OpenIFS@home ensemble (a, d), in the IFS experiment (b, e), and in the operational forecast (c, f). The vertical blue line indicates the verification as derived from ECMWF's analysis. Mean sea level pressure data are for a $60 \mathrm{~h}$ forecast lead time. Total precipitation data are accumulated between forecast lead times of 60 to $72 \mathrm{~h}$.

We discuss here the results of the OpenIFS@home forecast using 2000 ensemble members run at a horizontal resolution of approx. $125 \mathrm{~km}$ (the T159 spectral resolution). These forecasts will be contrasted with two 51-ensemble member forecasts of the IFS run on the ECMWF supercomputer: a low-resolution experiment also at $125 \mathrm{~km}$ (T159) resolution and the operational forecast at the time of TC Karl, which has a resolution of approx. $18 \mathrm{~km}$ (T1279) that is almost an order of magnitude finer. ECMWF's operational weather forecasts are comprised of 51 individual ensemble members and serves here as a benchmark.

The OpenIFS@ @ome ensemble predicted a distribution of surface pressure averaged over the northern Scotland area with a mean of approx. $1011 \mathrm{hPa}$ and a long tail towards low-pressure values (Fig. 4a). The analysis value of $1001 \mathrm{hPa}$ is just at the lowest edge of the distribution, indicating that while the OpenIFS@ home model was able to assign a nonzero probability to this extreme outcome, it did not indicate a seriously large risk for such small values. In comparison, the forecast with the standard operational prediction ensemble size of 51 members (Fig. 4b) did not even include the observed minimum in its tails, implying that the observed event was virtually impossible to occur. This clearly demonstrates the power of our large ensemble which, while not assigning a significant probability to the observed outcome, did include it as a possible though unlikely outcome. The overestimation of the surface pressure in the OpenIFS@home forecasts is hardly surprising because the magnitude of pressure minima strongly depends on the horizontal model resolution. For ex- ample, the operational high-resolution ECMWF forecast is shown in Fig. 4c. The distribution is nearly uniformly distributed between 999 and $1012 \mathrm{hPa}$. The analysis value lies well within that range, though interestingly it is at a local minimum of the distribution. With the application of suitable calibration or adjustment for the horizontal model resolutiondependent underestimation bias in the surface pressure mean, the example of TC Karl demonstrates the power of large ensembles to assign non-zero probabilities to extreme outcomes at the very tails of the distribution

The precipitation forecasts for northern Scotland are shown in Fig. 4d-f. OpenIFS@ home forecasts a substantial probability to the possibilities of rainfall values larger than the analysis. A traditional-sized ensemble of the same horizontal resolution considers the observed outcome much less likely than the large OpenIFS@ home ensemble. The highresolution forecast at operational resolution arguably did not perform much better than OpenIFS@home even though the low-pressure system itself would be better simulated.

The forecasts of surface pressure and precipitation over the region near Bergen are shown in Fig. 5. Similar to the performance north of Scotland, the large ensemble of OpenIFS@home (Fig. 5a) does include in its distribution the observed low-pressure value, while in the case of a 51member IFS T159 ensemble even the lowest forecast value was above the analysis (Fig. 5b). The high-resolution operational IFS forecast (Fig. 5c) gave a higher probability to the observed outcome than OpenIFS@ @ome but also considered it extreme within its predicted range. 
(a)

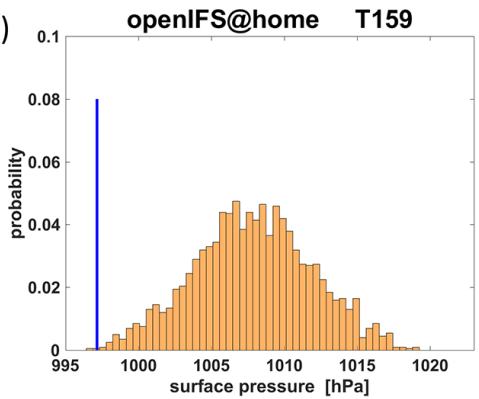

(d)

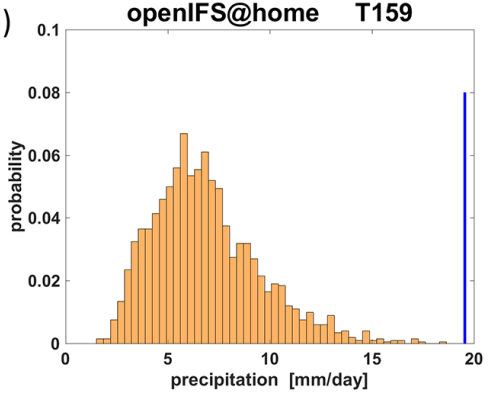

(b)

b) 0.3

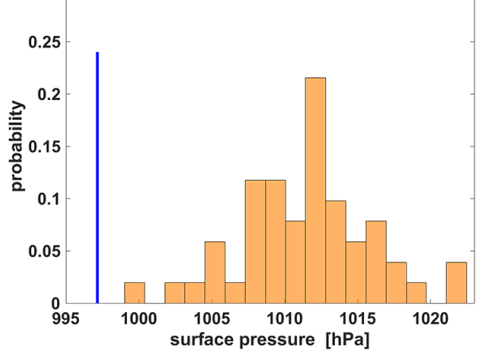

(e)

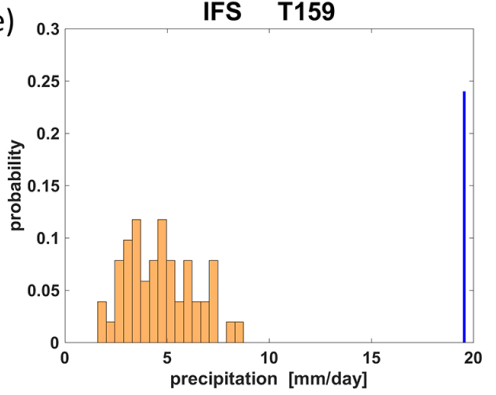

(c)

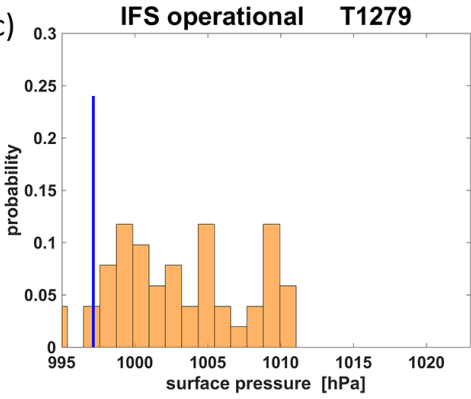

(f)

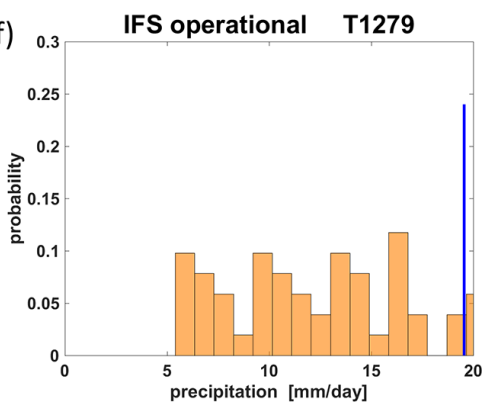

Figure 5. Ensemble forecast distribution near Bergen of mean sea level pressure (a-c) and total precipitation (d-f) in the OpenIFS@ home ensemble (a, d), in the IFS experiment $(\mathbf{b}, \mathbf{e})$, and in the operational forecast $(\mathbf{c}, \mathbf{f})$. The vertical blue line indicates the verification as derived from ECMWF's analysis. Mean sea-level pressure data are for a $72 \mathrm{~h}$ forecast lead time. Total precipitation data are accumulated between forecast lead times of 60 and $72 \mathrm{~h}$.

The extreme precipitation amount of nearly $20 \mathrm{~mm} \mathrm{~d}^{-1}$ in the analysis for the region around Bergen was only captured by the high-resolution operational IFS forecast (Fig. 5f) which is likely a result of the much improved representation of the small-scale orography over the coast of Norway in runs with high horizontal resolution, with implications for orographic rain amounts. While the entire distribution of the 51-member IFS ensemble was far off the observed amount without any indication of possibly more extreme outcomes (Fig. 5e), the large ensemble of OpenIFS@ home (Fig. 5d) produced a long tail towards extreme precipitation amounts which nearly reached $20 \mathrm{~mm} \mathrm{~d}^{-1}$.

The forecast accuracy of the extreme meteorological conditions of TC Karl is influenced by three key factors: (i) a good physical model that can simulate the atmospheric flow in highly baroclinic extratropical conditions as an extratropical low-pressure system; (ii) a higher horizontal resolution that allows a better resolution of the storm, and (iii) a large ensemble that samples a wide range of uncertainties given the simulated flow for a given resolution. OpenIFS@home is built on the world-leading Numerical Weather Prediction (NWP) forecast model of ECMWF that enables our distributed forecasting system to use the most advanced science of weather prediction. Arguably, a storm like Karl will be better resolved with higher horizontal resolution, as becomes clear in our demonstration of the IFS performance in two contrasting resolutions. However, there are other meteorological phenomena where horizontal resolution does not play a similarly large role in the successful prediction of extreme events. For these situations, the availability of very large ensembles that enable a meaningful sampling of the tails of the distribution, and with it the risks for extreme outcomes, will be most valuable. Our TC Karl analysis has made that point very clear by showing a substantial improvement in the probabilistic forecasts of both very low surface pressure (and associated winds) and large rainfall totals.

\section{Conclusions}

This paper introduced the OpenIFS@home project (version 1) that enables the production of very large ensemble weather forecasts, supporting types of studies previously too computationally expensive to attempt and growing the research community able to access OpenIFS. This was completed with the help of citizen scientists who volunteered computational resources and the deployment of the ECMWF OpenIFS model within the CPDN infrastructure as the OpenIFS@ home application. The work is based on the ClimatePrediction.net and weather@home systems enabling a simpler and more sustainable deployment.

We validated the first use of OpenIFS@home in a volunteer computing framework for ensemble forecast simulations using the example of TC Karl (September 2016) over the North Atlantic. Forecasts with 2000 ensemble members were generated for $6 \mathrm{~d}$ ahead and computed by volunteers within $\sim 3 \mathrm{~d}$. Significantly smoother probability distribution can be created than forecasts generated with significantly fewer en- 
semble members. In addition, the very large ensemble can represent the uncertainty better, particularly in the tails of the forecast distributions, allowing higher accuracy of the probability of extremes of the forecast distribution. The relatively low horizontal resolution of OpenIFS@home when compared with typical operational NWP resolutions and the potential implications due to the resolution are, however, a limitation that always must be kept in mind for specific applications. This system has significant future potential and offers opportunities to address topical scientific investigation, some of examples of which are listed below.

- Performing comprehensive sensitivity analyses to attribute sources of uncertainty, which dominate the meteorological forecasts and meteorological analyses directing where to allocate resources for future research, i.e. understanding how much meteorological uncertainty is generated through the land surface parameterization in comparison to the ocean.

- Investigating the tails of distribution and forecast outliers which are important for risk-based decisionmaking, particularly in high-impact, low-probability scenarios, e.g. tropical cyclone landfall.

- Improving the understanding of non-linear interactions of all Earth system components and their uncertainties will provide valuable insight into fundamental model processes. Not only will large initial conditions ensembles be possible but so will large multi-model perturbed parameter experiments.
We have demonstrated that the current application as deployed produces scientifically relevant results within a useful time frame, whilst utilizing acceptable amounts of computational resources on volunteering citizen scientist's personal computers. However, further developments have been identified as desirable in the future use of the facility. For instance, developing a working application for Windows (and MacOS) systems would significantly increase the number of volunteers available to compute OpenIFS@home simulations, which in turn would result in a reduction in queue time for simulations and engage public volunteers from a wider community. Another possible future development will look at utilizing multiple cores via the OpenMP multi-threading capability of OpenIFS. As new versions of the OpenIFS model are released, the OpenIFS@Home facility will be updated as resources allow.

In terms of potential areas of future scientific use of openIFS@home, research on understanding and predicting compound extreme events (for example, a heat wave in conjunction with a meteorological and hydrological drought) will be of interest. ECMWF's operation ensemble size of 51 members makes such investigations very difficult and limited in their scope, while the very large ensemble setup of openIFS@home provides an ideal framework for the required sample sizes of multivariate studies. We are planning to use the system for predictability research on a range of timescales from days to weeks and months, with potential idealized climate applications also feasible in the longer term. 


\section{Appendix A: OpenIFS description}

OpenIFS uses a hydrostatic dynamical core for all forecast resolutions, with prognostic equations for the horizontal wind components (vorticity and divergence), temperature, water vapour, and surface pressure. The hydrostatic, shallowatmosphere approximation primitive equations are solved using a two-time-level, semi-implicit semi-Lagrangian formulation (Hortal, 2002; Ritchie et al., 1995; Staniforth and Côté, 1991; Temperton et al., 2001). OpenIFS is a global model and does not have the capability for limited-area forecasts.

The dynamical core is based on the spectral transform method (Orszag, 1970; Temperton, 1991). Fast Fourier transforms (FFTs) in the zonal direction and Legendre transforms (LT) in the meridional direction are used to transform the representation of variables to and from grid point to spectral space. The spectral representation is used to compute horizontal derivatives, efficiently solve the Helmholtz equation associated with the semi-implicit time-stepping scheme, and apply horizontal diffusion. The computation of semiLagrangian horizontal advection, the physical parameterizations, and the non-linear right-hand-side terms are all computed in grid point space. The horizontal resolution is therefore represented by both the spectral truncation wavenumber (the number of retained waves in spectral space) and the resolution of the associated Gaussian grid. Gaussian grids are regular in longitude but slightly irregular in latitude with no polar points. Model resolutions are usually described using a Txxx notation where $\mathrm{xxx}$ is the number of retained waves in spectral representation. In the vertical, a hybrid sigmapressure-based coordinate is used, in which the lowest layers are pure so-called "sigma" levels, whilst the topmost model levels are pure pressure levels (Simmons and Burridge, 1981). The vertical resolution varies smoothly with geometric height and is finest in the planetary boundary layer, becoming coarser towards the model top. A finite-element scheme is used for the vertical discretization (Untch and Hortal, 2004). In this paper, all OpenIFS@home forecasts used the T159 horizontal resolution on a linear model grid with 60 vertical levels. This approximates to a resolution of $125 \mathrm{~km}$ at the Equator or a "N80" grid.

The OpenIFS model includes a comprehensive set of subgrid parameterizations representing radiative transfer, convection, clouds, surface exchange, turbulent mixing, subgrid-scale orographic drag, and non-orographic gravity wave drag. The radiation scheme uses the Rapid Radiation Transfer Model (RRTM) (Mlawer et al., 1997) with cloud radiation interactions using the Monte Carlo Independent Column Approximation (McICA) (Morcrette et al., 2008). Radiation calculations of short- and long-wave radiative fluxes are done less frequently than the time step of the model and on a coarser grid. This is relevant for implementation in the BOINC framework because this calculation of the fluxes represents the high-water memory usage of the model. The moist convection scheme uses a mass-flux approach repre- senting deep, shallow, and mid-level convection (Bechtold et al., 2008; Tiedtke, 1989), with a recent update to the convective closure for significant improvements in the convective diurnal cycle (Bechtold et al., 2014). The cloud scheme is based on Tiedtke (1993) but with an enhanced representation of mixed-phase clouds and prognostic precipitation (Forbes and Tompkins, 2011; Forbes et al., 2011). The HTESSEL tiled surface scheme represents the surface fluxes of energy and water and the corresponding sub-surface quantities. Surface sub-grid types of vegetation, bare soil, snow, and open water are represented (Balsamo et al., 2009). Unresolved orographic effects are parameterized according to Beljaars et al. (2004) and Lott and Miller (1997). Non-orographic gravity waves are parameterized according to Orr et al. (2010). The sea surface has a two-way coupling to the ECMWF wave model (Janssen, 2004). Monthly mean climatologies for aerosols, long-lived trace gases, and surface fields such as sea surface temperature are read from external fields provided with the model package. Although IFS includes an ocean model for operational forecasts, OpenIFS does not include it.

In order to represent random model error due to unresolved sub-grid-scale processes, OpenIFS includes the stochastic parameterization schemes of IFS (see Leutbecher et al., 2017, for an overview). For example, the SPPT scheme perturbs the total tendencies from all physical parameterizations using a multiplicative noise term (Buizza et al., 2007; Palmer et al., 2009; Shutts et al., 2011). 
Code availability. The BOINC implementation of OpenIFS, as distributed by CPDN, includes a free personal binary-only license to use the custom OpenIFS binary executable on the volunteer computer. Researchers who need to modify the OpenIFS source code for use in OpenIFS@ home must have an OpenIFS software source code license.

A software licensing agreement with ECMWF is required to access the OpenIFS source distribution: despite the name it is not provided under any form of open-source software license. License agreements are free, limited to non-commercial use, forbid any realtime forecasting, and must be signed by research or educational organizations. Personal licenses are not provided. OpenIFS cannot be used to produce or disseminate real-time forecast products. ECMWF has limited resources to provide support and thus may temporarily cease issuing new licenses if it is deemed too difficult to provide a satisfactory level of support. Provision of an OpenIFS software license does not include access to ECMWF computers or data archives other than public datasets.

OpenIFS requires a version of the ECMWF ecCodes GRIB library for input and output: version 2.7.3 was used in this paper (though results are not dependent on the version). All required ecCodes files, such as the modified GRIB templates, are included in the application tarfile available from Centre for Environmental Data Analysis (http://www.ceda.ac.uk, last access: 1 June 2021, see data availability section below for details). Version $2.7 .3 \mathrm{of} \mathrm{ec-}$ Codes can also be downloaded from the ECMWF GitHub repository (https://github.com/ecmwf, last access: 1 June 2021, ECMWF, 2021), though note that the modified GRIB templates included in the application tarfile must be used.

Parties interested in modifying the model source code should contact ECMWF, by emailing openifs-support@ecmwf.int, to request a license outlining their proposed use of the model. Consideration may be given to requests that are judged to be beneficial for future ECMWF scientific research plans or those from scientists involved in new or existing collaborations involving ECMWF. See the following webpage for more details: https://software.ecmwf.int/oifs (last access: 1 June 2021).

All bespoke code that has been produced in the creation of OpenIFS@home is kept in a set of publicly available open-source GitHub repositories under the CPDN-Git organization (https:// github.com/CPDN-git, last access: 1 June 2021). The exact release versions (1.0.0) are archived on Zenodo (Bowery and Carver 2020; Sparrow, 2020a-c; Uhe and Sparrow, 2020).

The OpenIFS@home binary application code version 2.19, together with the post-processing and plotting scripts used to analyse and produce the figures in this paper, are included within the deposit at the CEDA data archive (details provided in the data availability section).

Data availability. The initial conditions used for the Tropical Cyclone Karl forecasts described in this paper, together with the full set of model output data for the experiment used in this study, are freely available (Sparrow et al., 2021) at the Centre for Environmental Data Analysis (http://www.ceda.ac.uk, last access: 1 June 2021).

Author contributions. SS was instrumental in specifying overall concept as well as the BOINC application design for
OpenIFS@home; developed web interfaces for generating ensembles, managing ancillary data files, and monitoring distribution of ensembles; and wrote the training documentation. $\mathrm{AB}$ developed the BOINC application for OpenIFS@home that is distributed to client machines and wrote scripts for submission of OpenIFS@home ensembles into the CPDN system. GDC developed the BOINC version of OpenIFS deployed in OpenIFS@ home. MOK contributed to the preparation of the experiment initial conditions. PO generated the perturbed initial states. DW was influential in specifying the overall concept and the specific BOINC application design of OpenIFS@home. FP was influential in the development of OpenIFS@home. AW was instrumental in the conceptual idea of using OpenIFS as a state-of-the-art weather prediction model for citizen science large-ensemble simulations. AW also developed some of the diagnostics. All authors contributed to the writing of the manuscript.

Competing interests. The authors declare that they have no conflict of interest.

Acknowledgements. We gratefully acknowledge the personal computing time given by the CPDN moderators for this project. We are grateful for the assistance provided by ECMWF for solving the GRIB encoding issue for very large ensemble member numbers.

Review statement. This paper was edited by Volker Grewe and reviewed by Wilco Hazeleger and Thomas M. Hamill.

\section{References}

Allen, M.: Do-it-yourself climate prediction, Nature, 401, 642, https://doi.org/10.1038/44266, 1999.

Anderson, D. P.: BOINC: A system for public-resource computing and storage, in: GRID '04: Proceedings of the 5th IEEE/ACM International Workshop on Grid Computing, 4-10, https://doi.org/10.1109/GRID.2004.14, 2004.

Balsamo, G., Viterbo, P., Beijaars, A., van den Hurk, B., Hirschi, M., Betts, A. K., and Scipal, K.: A revised hydrology for the ECMWF model: Verification from field site to terrestrial water storage and impact in the integrated forecast system, J. Hydrometeorol. 10, 623-643, https://doi.org/10.1175/2008JHM1068.1, 2009.

Bechtold, P., Köhler, M., Jung, T., Doblas-Reyes, F., Leutbecher, M., Rodwell, M. J., Vitart, F., and Balsamo, G.: Advances in simulating atmospheric variability with the ECMWF model: From synoptic to decadal time-scales, Q. J. Roy. Meteor. Soc., 134, 1337-1351, https://doi.org/10.1002/qj.289, 2008.

Bechtold, P., Semane, N., Lopez, P., Chaboureau, J. P., Beljaars, A., and Bormann, N.: Representing equilibrium and nonequilibrium convection in large-scale models, J. Atmos. Sci., 71, 734-753, https://doi.org/10.1175/JAS-D-13-0163.1, 2014.

Beljaars, A. C. M., Brown, A. R., and Wood, N.: A new parametrization of turbulent orographic form drag, Q. J. Roy. Meteor. Soc., 130, 1327-1347, https://doi.org/10.1256/qj.03.73, 2004. 
Bowery, A. and Carver, G.: Instructions and code for controlling ECMWF OpenIFS application in ClimatePrediction.net (CPDN) [code],=, Zenodo, https://doi.org/10.5281/zenodo.3999557, 2020.

Buizza, R., Milleer, M., and Palmer, T. N.: Stochastic representation of model uncertainties in the ECMWF ensemble prediction system, Q. J. Roy. Meteor. Soc., 125, 2887-2908, https://doi.org/10.1002/qj.49712556006, 2007.

Buizza, R., Leutbecher, M., and Isaksen, L.: Potential use of an ensemble of analyses in the ECMWF Ensemble Prediction System, Q. J. Roy. Meteor. Soc., 134, 2051-2066, https://doi.org/10.1002/qj.346, 2008.

Christensen, C., Aina, T., and Stainforth, D.: The challenge of volunteer computing with lengthy climate model simulations, Proceedings of the 1st IEEE Conference on e-Science and Grid Computing, Melbourne, Australia, 5-8 December 2005.

ClimatePrediction.net: OpenIFS@ home dashboard, available at: https://dev.cpdn.org/oifs_dashboard.php (last access: 29 June 2020), 2019.

Daventry, M.: Climate Now I Five ways you can become a citizen scientist and help save the planet, EuroNews, available at: https://www.euronews.com/2020/12/17/climate-now-how-tobecome-a-citizen-scientist-and-help-, save-the-planet (last access: 25 January 2021), 2020.

ECMWF: IFS Documentation CY40R1 - Part III: Dynamics and Numerical Procedures, ECMWF, https://doi.org/10.21957/khi5o80, 2014a.

ECMWF: IFS Documentation CY40R1 - Part IV: Physical Processes, ECMWF, https://doi.org/10.21957/f56vvey1x, 2014b.

ECMWF: IFS Documentation CY40R1 - Part VI: Technical and computational procedures, ECMWF, https://doi.org/10.21957/19d0p4edi, 2014c.

ECMWF: IFS Documentation CY40R1 - Part VII: ECMWF Wave Model, ECMWF, https://doi.org/10.21957/jp6ffnj, 2014d.

ECMWF: ECMWF GitHub repository, available at: https://github. com/ecmwf, last access: 1 June 2021,

Euler, C., Riemer, M., Kremer, T., and Schömer, E.: Lagrangian description of air masses associated with latent heat release in tropical Storm Karl (2016) during extratropical transition, Mon. Weather Rev., 147, 2657-2676, https://doi.org/10.1175/MWRD-18-0422.1, 2019.

Forbes, R. and Tompkins, A.: An improved representation of cloud and precipitation, ECMWF Newsletter No. 129, 13-18, https://doi.org/10.21957/nfgulzhe, 2011.

Forbes, R. M., Tompkins, A. M., and Untch, A.: A new prognostic bulk microphysics scheme for the IFS, ECMWF Technical Memorandum No. 649, 22 pp., https://doi.org/10.21957/bf6vjvxk, 2011.

Fountain, H.: Looking, quickly, for the fingerprints of climate change, available at: https://www.nytimes.com/2016/08/02/science/ looking-quickly-for-the-fingerprints-of-climate-change.html (last access: 25 January 2021), 2016.

Harr, P. A., Anwender, D., and Jones, S. C.: Predictability associated with the downstream impacts of the extratropical transition of tropical cyclones: Methodology and a case study of typhoon Nabi (2005), Mon. Weather Rev., 136, 3205-3225, https://doi.org/10.1175/2008MWR2248.1, 2008.
Hawkins, L. R., Rupp, D. E., McNeall, D. J., Li, S., Betts, R. A., Mote, P. W., Sparrow, S. N., and Wallom, D. C. H.: Parametric Sensitivity of Vegetation Dynamics in the TRIFFID Model and the Associated Uncertainty in Projected Climate Change Impacts on Western U.S. Forests, J. Adv. Model. Earth Sy., 11, 2787 2813, https://doi.org/10.1029/2018MS001577, 2019.

Hortal, M.: The development and testing of a new two-timelevel semi-Lagrangian scheme (SETTLS) in the ECMWF forecast model, Q. J. Roy. Meteor. Soc., 128, 1671-1687, https://doi.org/10.1002/qj.200212858314, 2002.

Isaksen, L., Bonavita, M., Buizza, R., Fisher, M., Haseler, J., Leutbecher, M., and Raynaud, L.: Ensemble of data assimilations at ECMWF, ECMWF Technical Memoranda No. 636, ECMWF, https://doi.org/10.21957/obke4k60, 2010.

Janssen, P. A. E. M.: The Interaction of Ocean Waves and Wind, Cambridge University Press, 385 pp., 2004.

Knight, C. G., Knight, S. H. E., Massey, N., Aina, T., Christensen, C., Frame, D. J., Kettleborough, J. A., Martin, A., Pascoe, S., Sanderson, B., Stainforth, D. A., and Allen, M. R.: Association of parameter, software, and hardware variation with large-scale behavior across 57,000 climate models, P. Natl. Acad. Sci. USA, 104, 12259-12264, https://doi.org/10.1073/pnas.0608144104, 2007.

Lang, S. T. K., Bonavita, M., and Leutbecher, M.: On the impact of re-centring initial conditions for ensemble forecasts, Q. J. Roy. Meteor. Soc., 141, 2571-2581, https://doi.org/10.1002/qj.2543, 2015.

Lang, S., Hólm, E., Bonavita, M., and Tremolet, Y.: A 50-member Ensemble of Data Assimilations, ECMWF Newsletter No. 158, 27-29, https://doi.org/10.21957/nb251xc4sl, 2019.

Leutbecher, M. and Lang, S. T. K.: On the reliability of ensemble variance in subspaces defined by singular vectors, Q. J. Roy. Meteor. Soc., 140, 1453-1466, https://doi.org/10.1002/qj.2229, 2014.

Leutbecher, M. and Palmer, T. N.: Ensemble forecasting, J. Comput. Phys., 227, 3515-3539, https://doi.org/10.1016/j.jcp.2007.02.014, 2008.

Leutbecher, M., Lock, S. J., Ollinaho, P., Lang, S. T. K., Balsamo, G., Bechtold, P., Bonavita, M., Christensen, H. M., Diamantakis, M., Dutra, E., English, S., Fisher, M., Forbes, R. M., Goddard, J., Haiden, T., Hogan, R. J., Juricke, S., Lawrence, H., MacLeod, D., Magnusson, L., Malardel, S., Massart, S., Sandu, I., Smolarkiewicz, P. K., Subramanian, A., Vitart, F., Wedi, N., and Weisheimer, A.: Stochastic representations of model uncertainties at ECMWF: state of the art and future vision, Q. J. Roy. Meteor. Soc., 143, 2315-2339, https://doi.org/10.1002/qj.3094, 2017.

Li, S., Rupp, D. E., Hawkins, L., Mote, P. W., McNeall, D., Sparrow, S. N., Wallom, D. C. H., Betts, R. A., and Wettstein, J. J.: Reducing climate model biases by exploring parameter space with large ensembles of climate model simulations and statistical emulation, Geosci. Model Dev., 12, 3017-3043, https://doi.org/10.5194/gmd-12-3017-2019, 2019.

Li, S., Otto, F. E. L., Harrington, L. J., Sparrow, S. N., and Wallom, D. C. H.: A pan-South-America assessment of avoided exposure to dangerous extreme precipitation by limiting to $1.5^{\circ} \mathrm{C}$ warming, Environ. Res. Lett., 15, 054005, https://doi.org/10.1088/1748-9326/ab50a2, 2020. 
Lott, F. and Miller, M. J.: A new subgrid-scale orographic drag parametrization: Its formulation and testing, Q. J. Roy. Meteor. Soc., 123, 101-127, https://doi.org/10.1002/qj.49712353704, 1997.

Margolis, J.: Gadgets that give back: awesome eco-innovations, from Turing Trust computers to the first sustainable phone, Financial Times, available at: https://www.ft.com/content/ eb1b1636-61d2-4c54-8524-ab92948331ae, last access: 25 January 2021.

Magnusson, L. and Källén, E.: Factors influencing skill improvements in the ECMWF forecasting system, Mon. Weather Rev., 141, 3142-3153, https://doi.org/10.1175/MWR-D-12-00318.1, 2013.

Millar, R. J., Otto, A., Forster, P. M., Lowe, J. A., Ingram, W. J., and Allen, M. R.: Model structure in observational constraints on transient climate response, Clim. Change, 131, 199-211, https://doi.org/10.1007/s10584-015-1384-4, 2015.

Mlawer, E. J., Taubman, S. J., Brown, P. D., Iacono, M. J., and Clough, S. A.: Radiative transfer for inhomogeneous atmospheres: RRTM, a validated correlated-k model for the longwave, J. Geophys. Res.-Atmos., 102, 16663-16682, https://doi.org/10.1029/97jd00237, 1997.

Morcrette, J. J., Barker, H. W., Cole, J. N. S., Iacono, M. J., and Pincus, R.: Impact of a new radiation package, McRad, in the ECMWF integrated forecasting system, Mon. Weather Rev., 136, 4773-4798, https://doi.org/10.1175/2008MWR2363.1, 2008.

Mulholland, D. P., Haines, K., Sparrow, S. N., and Wallom, D.: Climate model forecast biases assessed with a perturbed physics ensemble, Clim. Dynam., 49, 1729-1746, https://doi.org/10.1007/s00382-016-3407-x, 2017.

Oregon State University: "weather@home” offers precise new insights into climate change in the West, available at: https://phys. org/news/2016-06-weatherhome-precise-insights-climate-west. html (last access: 25 January 2021), 2016.

Orr, A., Bechtold, P., Scinocca, J., Ern, M., and Janiskova, M.: Improved middle atmosphere climate and forecasts in the ECMWF model through a nonorographic gravity wave drag parameterization, J. Climate, 23, 5905-5926, https://doi.org/10.1175/2010JCLI3490.1, 2010.

Orszag, S. A.: Transform Method for the Calculation of Vector-Coupled Sums: Application to the Spectral Form of the Vorticity Equation, J. Atmos. Sci., 27, 890-895, https://doi.org/10.1175/15200469(1970)027<0890:TMFTCO>2.0.CO;2, 1970.

Otto, F. E. L., Massey, N., van Oldenborgh, G. J., Jones, R. G., and Allen, M. R.: Reconciling two approaches to attribution of the 2010 Russian heat wave, Geophys. Res. Lett., 39, L04702, https://doi.org/10.1029/2011GL050422, 2012.

Palmer, T. N., Buizza, R., Doblas-Reyes, F., Jung, T., Leutbecher, M., Shutts, G. J., Steinheimer, M., and Weisheimer, A.: 598 Stochastic Parametrization and Model Uncertainty, available at: http://www.ecmwf.int/publications/ (last access: 22 June 2020), 2009

Philip, S., Sparrow, S., Kew, S. F., van der Wiel, K., Wanders, N., Singh, R., Hassan, A., Mohammed, K., Javid, H., Haustein, K., Otto, F. E. L., Hirpa, F., Rimi, R. H., Islam, A. K. M. S., Wallom, D. C. H., and van Oldenborgh, G. J.: Attributing the 2017 Bangladesh floods from meteorological and hydro- logical perspectives, Hydrol. Earth Syst. Sci., 23, 1409-1429, https://doi.org/10.5194/hess-23-1409-2019, 2019.

Ritchie, H., Temperton, C., Simmons, A., Hortal, M., Davies, T., Dent, D., and Hamrud, M.: Implementation of the Semi-Lagrangian Method in a HighResolution Version of the ECMWF Forecast Model, Mon. Weather Rev., 123, 489-514, https://doi.org/10.1175/15200493(1995)123<0489:IOTSLM>2.0.CO;2, 1995.

Rowlands, D. J., Frame, D. J., Ackerley, D., Aina, T., Booth, B. B. B., Christensen, C., Collins, M., Faull, N., Forest, C. E., Grandey, B. S., Gryspeerdt, E., Highwood, E. J., Ingram, W. J., Knight, S., Lopez, A., Massey, N., McNamara, F., Meinshausen, N., Piani, C., Rosier, S. M., Sanderson, B. M., Smith, L. A., Stone, D. A., Thurston, M., Yamazaki, K., Hiro Yamazaki, Y., and Allen, M. R.: Broad range of 2050 warming from an observationally constrained large climate model ensemble, Nat. Geosci., 5, 256-260, https://doi.org/10.1038/ngeo1430, 2012.

Royal Society for the Protection of Birds (RSPB): Big Garden BirdWatch, available at: https://www.rspb.org.uk/get-involved/ activities/birdwatch/, last access: 15 January 2021.

Rupp, D. E., Li, S., Massey, N., Sparrow, S. N., Mote, P. W., and Allen, M.: Anthropogenic influence on the changing likelihood of an exceptionally warm summer in Texas, 2011, Geophys. Res. Lett., 42, 2392-2400, https://doi.org/10.1002/2014GL062683, 2015.

Schäfler, A., Craig, G., Wernli, H., Arbogast, P., Doyle, Ja. D., Mctaggart-Cowan, R., Methven, J., Rivière, G., Ament, F., Boettcher, M., Bramberger, M., Cazenave, Q., Cotton, R., Crewell, S., Delanoë, J., DörnbrAck, A., Ehrlich, A., Ewald, F., Fix, A., Grams, C. M., Gray, S. L., Grob, H., Groß, S., Hagen, M., Harvey, B., Hirsch, L., JAcob, M., Kölling, T., Konow, H., Lemmerz, C., Lux, O., Magnusson, L., Mayer, B., Mech, M., Moore, R., Pelon, J., Quinting, J., Rahm, S., Rapp, M., Rautenhaus, M., Reitebuch, O., Reynolds, C. A., Sodemann, H., Spengler, T., Vaughan, G., Wendisch, M., Wirth, M., Witschas, B., Wolf, K., and Zinner, T.: The north atlantic waveguide and downstream impact experiment, B. Am. Meteorol. Soc., 99, 16071637, https://doi.org/10.1175/BAMS-D-17-0003.1, 2018.

Schaller, N., Kay, A. L., Lamb, R., Massey, N. R., van Oldenborgh, G. J., Otto, F. E. L., Sparrow, S. N., Vautard, R., Yiou, P., Ashpole, I., Bowery, A., Crooks, S. M., Haustein, K., Huntingford, C., Ingram, W. J., Jones, R. G., Legg, T., Miller, J., Skeggs, J., Wallom, D., Weisheimer, A., Wilson, S., Stott, P. A., and Allen, M. R.: Human influence on climate in the 2014 southern England winter floods and their impacts, Nat. Clim. Change, 6, 627-634, https://doi.org/10.1038/nclimate2927, 2016.

Shutts, G., Leutbecher, M., Weisheimer, A., Stockdale, T., Isaksen, L., and Bonavita, M.: Representing model uncertainty: Stochastic parametrizations at ECMWF, ECMWF Newsletter, 129, 1924, https://doi.org/10.21957/fbqmkhv7, 2011.

Simmons, A. J. and Burridge, D. M.: An Energy and Angular-Momentum Conserving Vertical Finite-Difference Scheme and Hybrid Vertical Coordinates, Mon. Weather Rev., 109, 758-766, https://doi.org/10.1175/15200493(1981)109<0758:AEAAMC>2.0.CO;2, 1981.

Simpson, R., Page, K. R., and De Roure, D.: Zooniverse: observing the world's largest citizen science platform, in: WWW'14: 23rd International World Wide Web Conference, Seoul, Korea, April 2014, https://doi.org/10.1145/2566486, 2014. 
Smyrk, K. and Minchin, L.: How your computer could reveal what's driving record rain and heat in Australia and NZ, available at: https://theconversation.com/how-your-computer-could-revealwhats-driving-record-rain-, and-heat-in-australia-and-nz-24804 (last access: 25 January 2021), 2014.

Sparrow, S.: OpenIFS@home submission xml generation scripts [code], Zenodo, https://doi.org/10.5281/zenodo.3999542, 2020a.

Sparrow, S.: OpenIFS@home ancillary file repository scripts [code], Zenodo, https://doi.org/10.5281/zenodo.3999551, $2020 \mathrm{~b}$.

Sparrow, S.: OpenIFS@home webpages and dashboard [code], Zenodo, https://doi.org/10.5281/zenodo.3999555, 2020c.

Sparrow, S., Su, Q., Tian, F., Li, S., Chen, Y., Chen, W., Luo, F., Freychet, N., Lott, F. C., Dong, B., Tett, S. F. B., and Wallom, D.: Attributing human influence on the July 2017 Chinese heatwave: The influence of sea-surface temperatures, Environ. Res. Lett., 13, 114004, https://doi.org/10.1088/1748-9326/aae356, 2018 a.

Sparrow, S., Millar, R. J., Yamazaki, K., Massey, N., Povey, A. C., Bowery, A., Grainger, R. G., Wallom, D., and Allen, M.: Finding Ocean States That Are Consistent with Observations from a Perturbed Physics Parameter Ensemble, J. Climate, 31, 4639-4656, https://doi.org/10.1175/JCLI-D-17-0514.1, $2018 \mathrm{~b}$.

Sparrow, S., Bowery, A., Carver, G., Koehler, M., Ollinaho, P., Pappenberger, F., Wallom, D., and Weisheimer, A.: OpenIFS@home: Ex-tropical cyclone Karl case study [data set], NERC EDS Centre for Environmental Data Analysis, available at: https://catalogue.ceda.ac.uk/ uuid/ed1bc64e34a14ca28fedd2731735d18a (last access: 1 June 2021), 2021.

Stainforth, D. A., Aina, T., Christensen, C., Collins, M., Faull, N., Frame, D. J., Kettleborough, J. A., Knight, S., Martin, A., Murphy, J. M., Piani, C., Sexton, D., Smith, L. A., Splcer, R. A., Thorpe, A. J., and Allen, M. R.: Uncertainty in predictions of the climate response to rising levels of greenhouse gases, Nature, 433, 403-406, https://doi.org/10.1038/nature03301, 2005.

Staniforth, A. and Côté, J.: Semi-Lagrangian Integration Schemes for Atmospheric Models - A Review, Mon. Weather Rev., 119, 2206-2223, https://doi.org/10.1175/15200493(1991)119<2206:SLISFA>2.0.CO;2, 1991.
Sullivan III, W. T., Werthimer, D., Bowyer, S., Cobb, J., Gedye, D., and Anderson, D.: A new major SETI project based on Project Serendip data and 100,000 personal computers, in: IAU Colloq. 161: Astronomical and Biochemical Origins and the Search for Life in the Universe, edited by: Batalli Cosmovici, C., Bowyer, S., and Werthimer, D., 729 pp., available at: https: //ui.adsabs.harvard.edu/abs/1997abos.conf..729S (last access: 22 June 2020), 1997.

Temperton, C.: On scalar and vector transform methods for global spectral models, Mon. Weather Rev., 119, 1303-1307, https://doi.org/10.1175/1520-0493-119-5-1303.1, 1991.

Temperton, C., Hortal, M., and Simmons, A.: A two-time-level semi-Lagrangian global spectral model, Q. J. Roy. Meteor. Soc., 127, 111-127, https://doi.org/10.1002/qj.49712757107, 2001.

Tiedtke, M.: A Comprehensive Mass Flux Scheme for $\mathrm{Cu}-$ mulus Parameterization in Large-Scale Models, Mon Weather Rev., 117, 1779-1800, https://doi.org/10.1175/15200493(1989)117<1779:ACMFSF>2.0.CO;2, 1989.

Tiedtke, M.: Representation of Clouds in Large-Scale Models, Mon. Weather Rev., 121, 3040-3061, https://doi.org/10.1175/15200493(1993)121<3040:ROCILS>2.0.CO;2, 1993.

Uhe, P. and Sparrow, S.: Code for sorting results uploaded to climatepredcition.net into project, batches and result status [software], Zenodo, https://doi.org/10.5281/zenodo.3999563, 2020.

Untch, A. and Hortal, M.: A finite-element scheme for the vertical discretization of the semi-Lagrangian version of the ECMWF forecast model, Q. J. Roy. Meteor. Soc., 130, 1505-1530, https://doi.org/10.1256/qj.03.173, 2004.

World Meteorological Organisation (WMO): Introduction to GRIB edition 1 and GRIB edition 2, available at: https://www.wmo.int/pages/prog/www/WMOCodes/Guides/ GRIB/Introduction_GRIB1-GRIB2.pdf (last access: 22 November 2019), 2003.

Yamazaki, K., Rowlands, D. J., Aina, T., Blaker, A. T., Bowery, A., Massey, N., Miller, J., Rye, C., Tett, S. F. B., Williamson, D., Yamazaki, Y. H., and Allen, M. R.: Obtaining diverse behaviors in a climate model without the use of flux adjustments, J. Geophys. Res.-Atmos., 118, 2781-2793, https://doi.org/10.1002/jgrd.50304, 2013. 